Behavioural Sciences | Peter C Hill

\title{
Can deeply religious people be intellectually humble?
}

Intellectual humility - the conscious awareness of the limits and fallibility of one's intelligen deeply religious people whose humility is tied to unquestioning deference to the divine? It is a question that both baffles and inspires those studying the psychology of religion. psychology at Rosemead Schoo has led a team to find a theistic - is a virtue in the search for wisdom. But is what's true Dr Peter C Hill, a professor of of Psychology, Biola University,

umility is considered a virtue by many religions. Similarly, centuries of philosophers have pointed to of finding the truth. Subbo a means to opinions hinders clarty of thought An open mind links to one of humilty's offhoots: intellectual humility It has multiple definitions, but it is generally the conscious awareness of the limits and fallibility of one's intelligence. If there's a motto for humility, it is in the purported words of Socrates: ' l know that I know nothing'. However, whereas in philosophy, humility is central to the search for wisdom, core to humility in religious texts is complete submission to divine authority. For the religious, humility is tied to deference. But such unquestioning allegiance appears to be incongruentwith the def ailion of thin

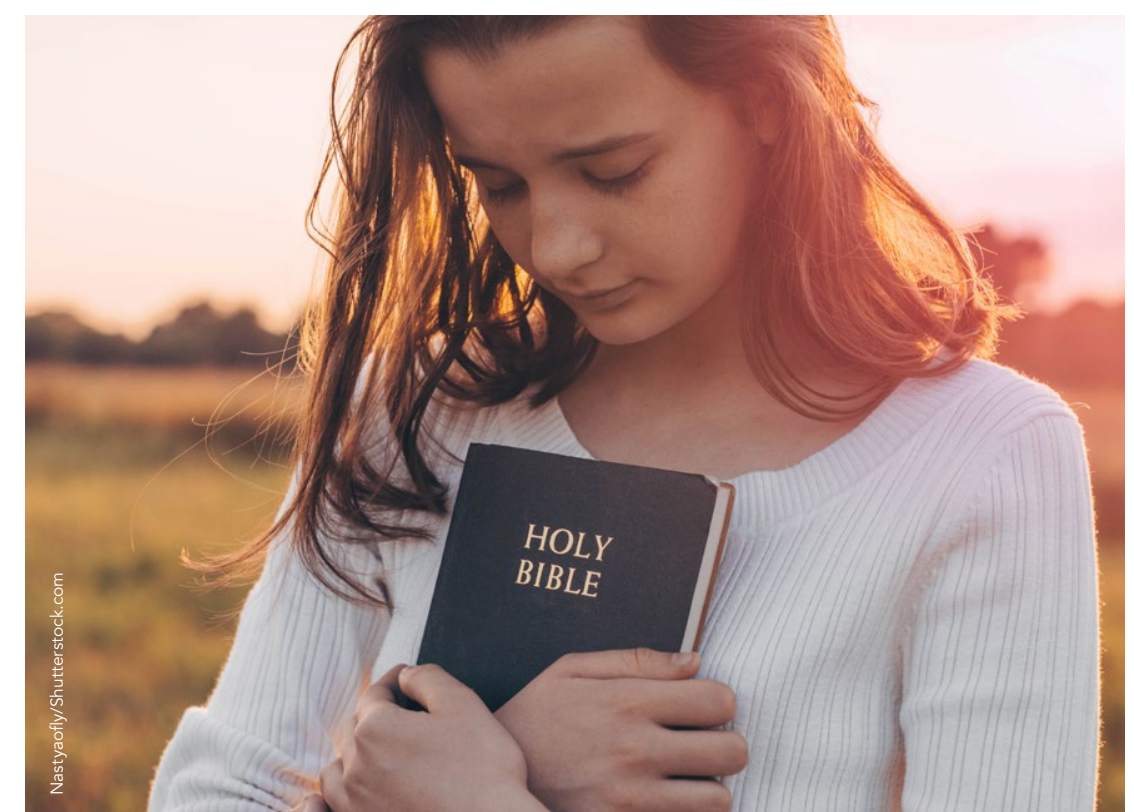

thought? Can deeply religious people also be intellectually humble? A team of pschiorsity a and phivesophers from Biola Lairada, have spent years trying to find out.

Dr Peter C Hill is a professor of psychology at the Rosemead School of Psychology based at Biola University Together with fellow psychologists, professors Elizabeth Lewis Hall and David Wang, and Professor Kent Dunnington, a philosopher at Biola, Hill has challenged the idea that people who hold strong religious beliefs are low in intellectual humility. They question the reasoning that intrapersonal intellectual humility would undermine strength in faith. Current research supporting this argument suggests that intellectual humility is not only negatively related to the strength of religious belief in general, in the divine, even to the point that it may affect their mental health and general wellbeing. Central to the team' research has been the speculation that an answer may lie in how we define and measure intellectual humility.

\section{THEISTIC INTELLECTUAL HUMILITY} (ntellectual humility is motivated by its potential to bridge increasingly polarised cultural corfers, sometmes linked to religious differences. However, the very prosocial variables related to intellectual humility, such as perspective-taking, empathetic concern, altruism, universalism and less power-seeking, appear incompatible with,
especially politically charged, religious

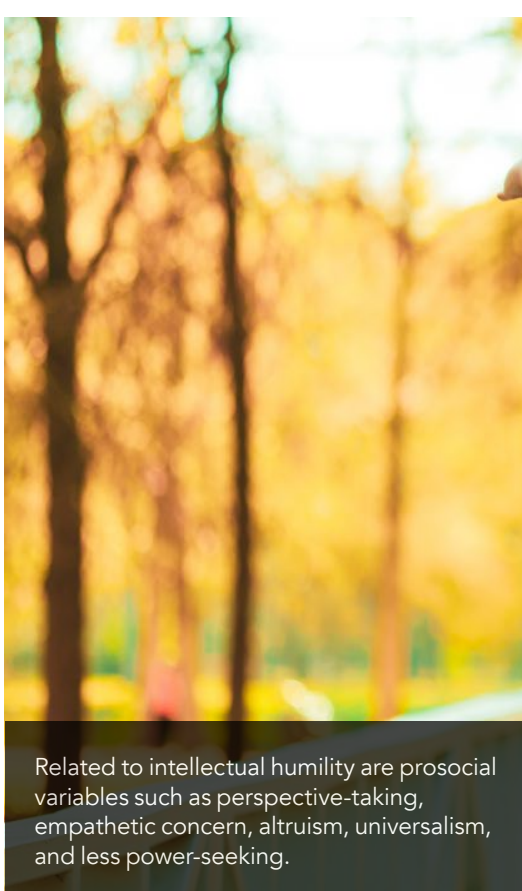

prior research into intellectual humility and theism in deeply religious - primarily evangelical Protestant - communities has found a negative or non-significant association. Interestingly, some researc humility in religious populations is of meaning and flourishing. If so, it seems incompatible with intellectual humily's status as a character strength. Why are intellecily s eudaemonic, supposedly so miserable?

Hill and his team suspected that an answer lies in the perceived commensurability and science, especially in their especially in their
chosen discipline -

the psychology of religion. In proposing a dialogical model between religion an science, they surmised that if the control beliefs in science differ with those of aith, they should design a measure of theistic intellectual humility - one that embraces its broader definition but is sensitive to cultural contexts. In a study supported by The John Templeman Foundation, they compiled list of 66 statements they considered expressive of mintectual humility from from leading philosophers, theologians

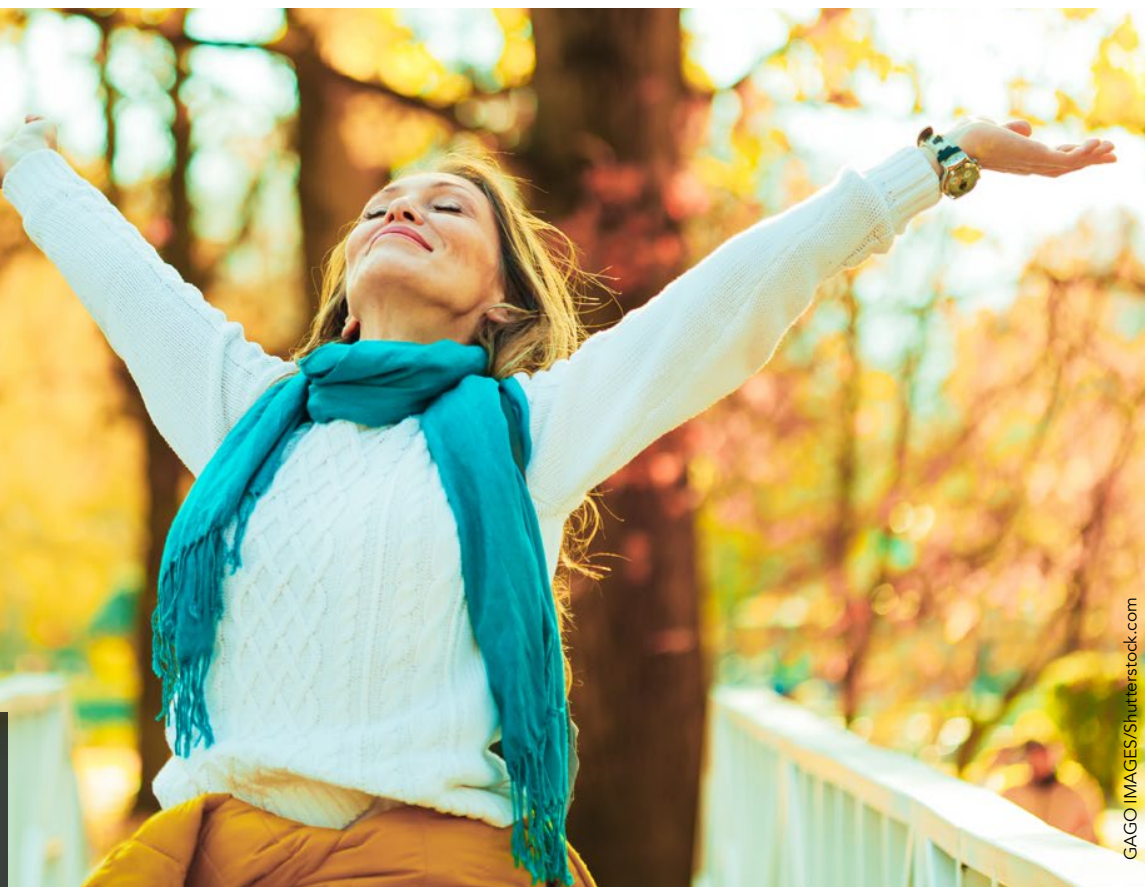

and psychologists who were specialists in humility, they expanded the list to 77 statements. Finally, they presented these statements in an online survey to Christian, with the instruction to rate each statement on a six-point scale
ranging from 'strongly disagree' to 'strongly agree'.

The 11 statements that seemed to best capture intellectual humility in this population broadly fell into three categories, or factors:

- Factor 1. In tellectual submission to intellectual humility is eudaemonic, y are intellectually humble theists supposedlly so miserable? understanding of the world depends
much on God revealing things to me.') - Factor 2: Human finite limitations (four statements, eg, I don't expect to have all my questions answered, but I am confident in God's knowledge.') - Factor 3: Belief bias and limitations (three statements, eg, 'I am not always sure my interpretations of the Bible are correct.')

The first two factors specifically address theistic beliefs - the degree to whic context of their relationship to God as personal transcendent being. Factor more on epistemological limitations and biases in comprehending the complexities of religious beliefs. For Hill and his team, these 11 statements would be the cornerstone of a theistic .

\section{TESTING THE TEST}

The best way to test their TIHS was to pit it against comparable scales. To respondis theam invited 296 of self-professed Christians and small liberal-arts Christian university to complete a series of 'standard' scales to measure intellectual humility, pride, closed-mindedness, social vigilantism and narcissistic personality, and a five-point personality inventory that measured extroversion, agreeableness, openness. The respondents then comp scale's constose was to test the for significt caldity by looking measures of intellectuat hum with sufficient divergence to represent the essence of the focus of the TIHS. 


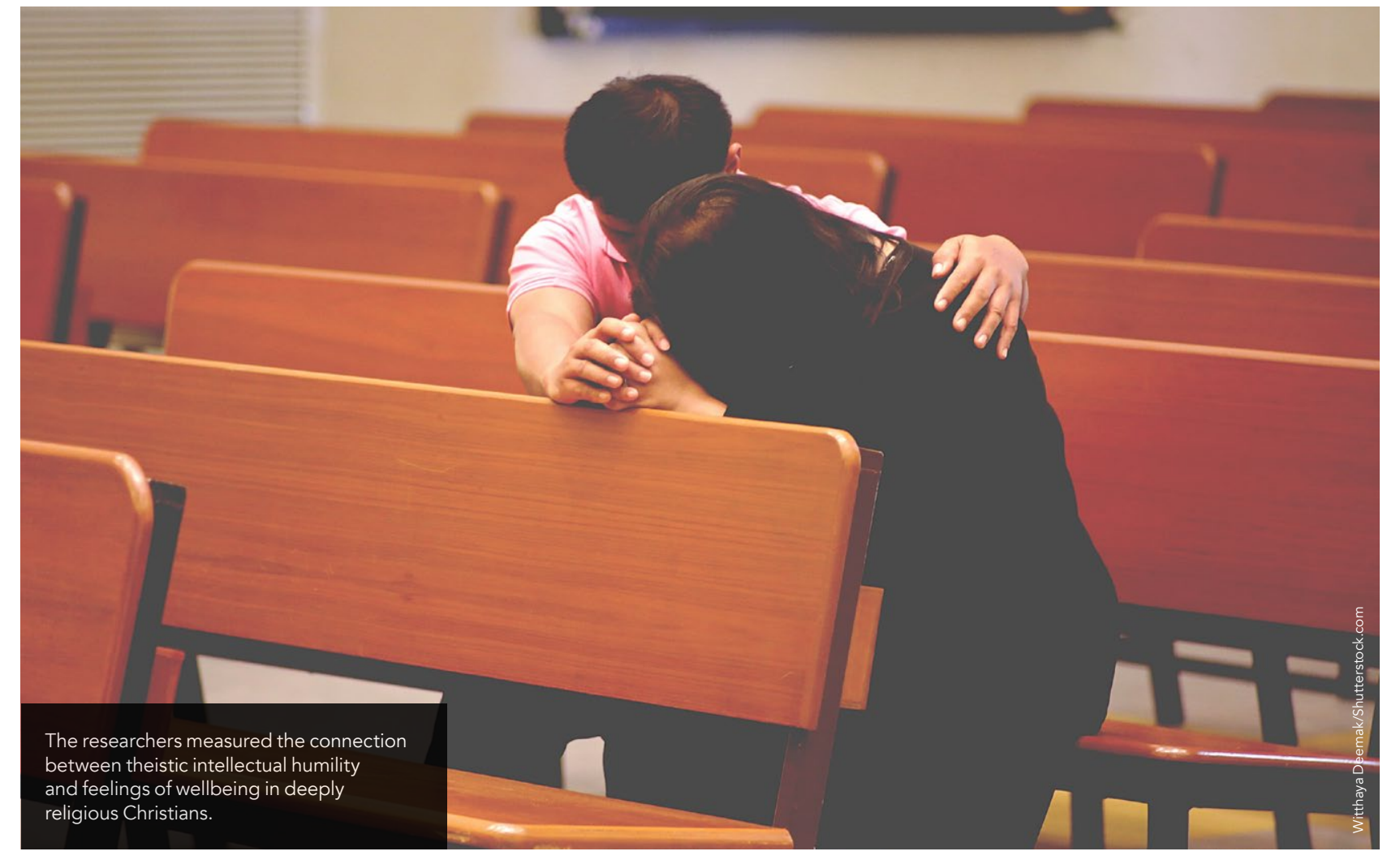

They expected that the TIHS and the would be either unrelated or slightly positively related. This was indeed the case, but it was primarily a function of the 'non-theistic' Factor 3 statements that pointed to belief bias and limitations of their religious beliefs. Therefore,
this factor was this factor was conceptually the
most similar of measures. But becintellectual humility team thought that the Hill and his Factors 1 and 2 would be independe of Factor 3 , they suspected the TIHS was tapping into a unique perspective of intellectual humility.

As the team expected, there was a positive correlation between the measures of the other scales linked to the concept of intellectual humility such as openness, authentic pride (as opposed to hubristic pride), and conscientiousness, and those of the TIHS especially the statements designed to predicted, the tho factors tha assessed

the extent to which the respondents of their theistic beliefs (Factors 1 and 2) functioned independently and sometim negatively with the third factor. But if th

The results showed that theistic heir THUS, sumility, as measured by several aspecticicantly moderated between religious commitment and flourishing. In fact, the total TIH scale significantly As religious commitment increases, a lack moderated four of of intellectual humility increases the risk measures.

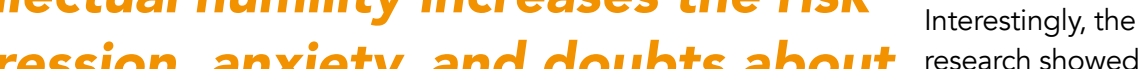
in, anxiety, and doubts about research showed ultimate meaning. that religious people with high levels of intellectual humility were unhappy?

\section{ISTIC INTELLECTUAL HUMILITY} AND WELLBEING

The research team decided the best way to answer this would be test with committed Christians, comparing their TIHS with scales designed to measure life satisfaction, mental health, an a subscale of the religious and spirituality scale that measures ultimate meaning. In brief. they measured the humility and feelings of wellbeng in that as religious
commitment increases, a lack of

intellectual humility increases the risk for depression, anxiety, and doubts about ultimate meaning.

Hill and his team acknowledge that their research has limitations, and their theistic intellectual humility scale should be tested and developed further to reflect the constructs of other religions. However, what cannot be ignored is tha they have forced us to re-evaluate how we should measure intellectual humility Perhaps on a bigger scale, their resear also suggests that before applying any scientic constructs to relyious experience, researchers should consider inder study believe.

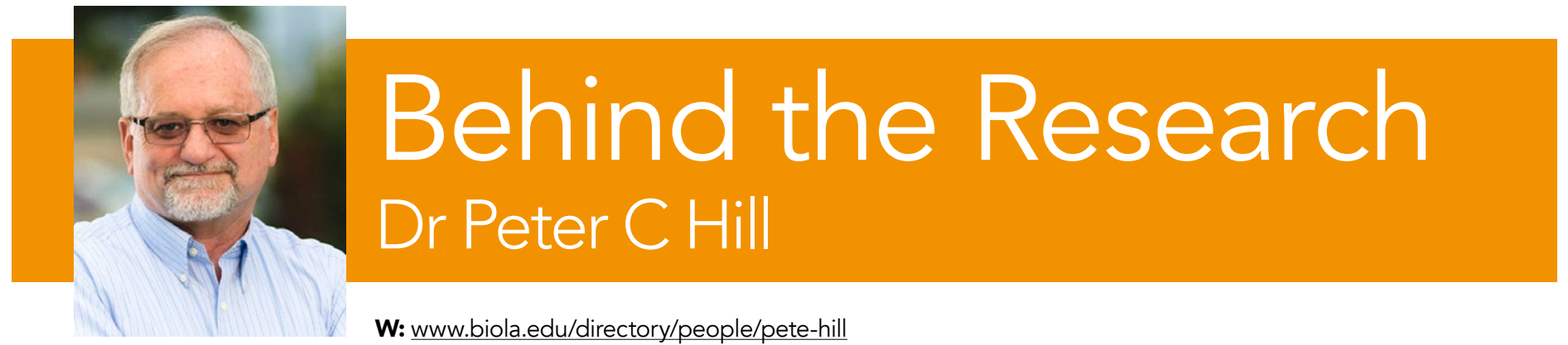

\section{Research Objectives}

Dr Hill and his team study intellectual humility among peoplew

\section{Detail}

\section{Address}

Office of Academic Research and Grants, Biola University, 13800 Biola Ave, La Mirada, CA 90639, USA

\section{Bio}

Peter C Hill, PhD, is Professor of Psychology at Rosemead School of Psychology, Biola University, in La Mirada,

California. Before that, he served for 17 years as Professor of Psychology at Grove City College in Pennsylvania. In 2006, he was honoured with a faculty appointment at the University of Cambridge as a Visiting Research Fellow at the Centre for Advanced Religious and Theological Studies of the Faculty of Divinity. He is an active researcher in social psychology and the psychology of religion and has authored approximately 150 articles in peer-reviewe journals and book chapters. He is a past president of Division 36 (Pychology or Religion) of the American Psychological Association (APA) and was elected Fellow
the APA in 1998.

Funding

The John Templeton Foundation

\section{Collaborators}

- Kent Dunningto

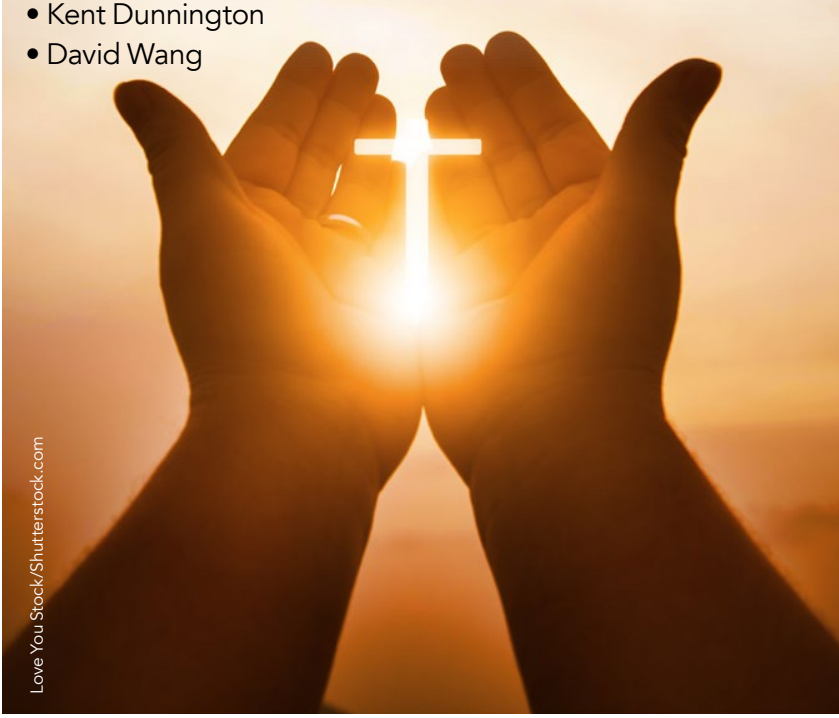

References Hill, PC, (2021) Intellectual humility in the psychology of
religion and spirituality. The International Journal for the Psychology of Religion. doi.org/10.1080/10508619.2021.1 916242

Hill, PC, Hall, MHL, Wang, D, Decker, LA, (2021) Theistic intellectual humility and well-being: does ideological contex matter? The Journal of Positive Psychology, 16(2), 155-167. dx.doi.org/10.1080/17439760.2019.1689424

Hill, PC, Dunnington, K, Hall, MHL, (2018) Glad intellectual dependence on God: A theistic account of intellectual

\section{Personal Response}

Your research into measuring intellectual humility emphasises the need for studies in the psychology what those under study believe. What other area of research in your field do you think is overdue for such a re-evaluation?

II The field of positive psychology is ripe for this kind of culturally sensitive refinement. Many of the concepts central to positive peans to live a good life, which is cultural and religious beliefs. We have suggested that moving forward, perhaps the field may need to move toward 'positive psychologies' rather than assuming that work in this area, which has largely been shaped by Western and secular assumptions, is relevant to all cultural
and religious groups.

(4) $\operatorname{BiOLAA}$ 